\title{
A Flow Injection System with Four Ion Exchange Resin Columns for Cadmium Pre-Concentration and Determination by Flame AAS
}

\author{
Carlos Eduardo Saraiva Miranda
}

Instituto de Química de São Carlos, Universidade de São Paulo

Boaventura Freire dos Reis* and Francisco José Krug

Centro de Energia Nuclear na Agricultura, Universidade de São Paulo, Av. Centenário, 303, C.P. 96, 13 416-000 Piracicaba-SP, Brazil

Received: March 21, 1995; May 12, 1995

\begin{abstract}
Desenvolveu-se um sistema de análise química por injeção em fluxo para efetuar pré-concentração de cádmio em linha, utilizando resina de troca iônica. A resina AG50W-X8 foi investigada, tendo em vista as facilidades de aplicação da metodologia desenvolvida em análises de rotina. $\mathrm{O}$ elemento de interesse foi determinado em digeridos de alimentos, empregando a espectrofotometria de absorção atômica com chama. O módulo de análise inclui quatro minicolunas de resina, tendo proporcionado uma velocidade analítica de 80 determinações por hora. Desvio padrão relativo menor que $2 \%(n=10)$ para uma amostra contendo $20 \mathrm{~g} \mathrm{Cd} / \mathrm{L}$ e limite de detecção de $0,7 \mathrm{~g} / \mathrm{L}$ foram algumas das características analíticas obtidas. A exatidão dos resultados obtidos foi confirmada analisando-se amostras de referência. Aplicando-se o test- $t$, não se verificou diferença significativa, ao nível de $5 \%$ de probabilidade, entre os resultados obtidos pelo método proposto e os correspondentes valores certificados.
\end{abstract}

A flow injection system comprised of four mini-columns packed with cation exchange resin was designed to implement an on-line pre-concentration procedure for cadmium determination by flame atomic absorption spectrophotometry. The AG50W-X8 resin behavior in the flow system was studied, taking into account its suitability for application to routine analysis. A throughput of up to 80 determinations per hour, and a detection limit of $0.7 \mathrm{ng} / \mathrm{L}$ were achieved. The relative standard deviation of measurements $(\mathrm{n}=10)$ for a sample with $20.0 \mathrm{~g} \mathrm{Cd} / \mathrm{L}$ was lower than $2 \%$. By applying the $t$-test at a probability level of $5 \%$ no significant was observed in comparing the results obtained by the proposed method and the certified values of standard reference materials.

Keywords: cadmium determination, on-line pre-concentration, ion exchange resin, flame $A A S$, flow analysis

\section{Introduction}

Flow injection analysis is nearly 20 years old ${ }^{1}$. Based on the knowledge gathered since it was introduced, analytical procedures involving either on-line dilution or pre-concentration steps have been proposed ${ }^{2,3}$. Liquid-liquid and solid-liquid extrations are the most frequent pre-concentration procedures employed to improve the limit of detection, mainly in association with spectrophotometric tech- niques $^{4,4}$. The reversible properties of the ion exchange resins make their use associated with flow techniques very attractive, since a column filled with resin can be used several times. For the determination of metallic cations, the Chelex-100 resin has been widely employed, mainly to analyze sea water by atomic absorption spectrometry ${ }^{5,6}$. Considering the low selectivity of this resin for alkaline metals, the flow manifolds have been designed to accomplish pre-concentration and matrix separation. 
The Chelex 100 resin behaves similarly to a weak acid, being highly selective for hydrogen ions ${ }^{7}$. Consequently, the pre-concentration process is more efficient in $\mathrm{pH}$ higher than 7. Another difficulty is the pronounced swelling effect, mainly observed when elution is performed by acid solutions and when the resin is conditioned in an ammonium medium before the pre-concentration step. The swelling effect promotes an increase in the hydrodynamic impedance of the flew system, which may cause fluid leakage at the joint points of the manifold.

The AG50W-X8 resin behaves as a strong acid, and therefore it has a higher ability to adsorb cations from solutions within a wider $\mathrm{pH}$ range when compared to the Chelex-100 resin. Other advantages are its negligible swelling effect and higher exchange capacity. However, it has seldom been used in analytical procedures ${ }^{9}$. Considering the properties of the AG50W-X8 resin, the possibility of using it to pre-cancentrate metallic ions in a flow injection system was investigated in this work.

Cadmium is a non-essential element in animal nutrition, and is toxic at low levels when accumulated in vital organs such as the kidneys and lungs. It can reach the food chain through different pathways, its monitoring being mandatory in the environment ${ }^{10}$. The determination of cadmium in low concentrations has often been carried out by flame atomic emission spectrometry ${ }^{11}$, and by molecular absorption spectrophotometry ${ }^{12}$. Therefore, considering the importance of eadmium determination, employing columns packed with AG50W-X8 resin to perform pre-concentration in a flow injection system was selected for testing.

When a resin column is coupled to the flow network, the increase in the analytical signal is associated with the volume of the sample solution pumped through the resin column. A resin column connected to the flow network causes an increase in the overall inner pressure. Therefore, the loading flow-rate cannot be increased at will, since a rupture in the flow system could occur. To prevent this from occuring, the loading time is increased, while the flow rate is decreased. To improve the limit of detection, generally the volume of sample pumped through the resin column is higher than that used to load the sampling loop in an usual flow system, resulting in a decrease of the sampling throughput. To overcome this disadvantage, a flow network employing four resin columns was designed. The pre-concentration step was performed simultaneously by the four minicolumns, the elution being carried out sequentially. Cadmium ions released from the columns were determined by flame atomic absorption spectrometry.

\section{Experimental}

\section{Apparatus}

Experiments were carried out with a Perkin-Elmer model 503 atomic absorption spectrometer, equipped with a cadmium hollow cathode lamp from the same manufacturer, and coupled to a REC 61 Radiometer Copenhagen strip chart recorder. An air $(15 \mathrm{~L} / \mathrm{min})$ - acetylene $(1.5$ $\mathrm{L} / \mathrm{min}$ ) flame was used throughout, and all measurements were made at $228.8 \mathrm{~nm}$. The nebulizer was adjusted for maximum sensitivity prior to flow injection coupling.

The flow set-up consisted of a mp13-GJ4 Ismatec peristaltic pump furnished with Tygon pumping tubes, a homemade automatic injector controlled by a microcomputer ${ }^{13}$, and four resin columns with interior volumes of about $216 \mu \mathrm{L}$ (11 mm length $\times 5 \mathrm{~mm}$ i.d.) drilled in a Perspex block as described elsewhere ${ }^{14}$. The columns were packed with AG50W-X8 resin (50-100 or 200-400 mesh) purchased from Bio Rad Labs in the hydrogen form. All flow lines were made of non-collapsible polyethylene tubing with a $0.8 \mathrm{~mm}$ inner diameter. A selecting switch for the analytical path with one inlet vial and four outlets was machined in Perspex. This device consisted of a rotator with drilled fluid outlets and a stator with a drilled fluid inlet. These pieces were helde together by means of a screw in order to avoid fluid leakage, but which allowed the displacement of the rotator to couple the fluid inlet with the selected outlet. A custom-made microcomputer ${ }^{13}$ based on the 8085 Intel microprocessor, with software written in assembly language was used for controlling all steps involved in the pre-concentration and elution processes.

\section{Solutions}

All chemicals were of analytical grade, and distilleddeionized water was used throughout.

Hydrochloric acid solutions of $1.0,2.0,3.0$ and $4.0 \mathrm{M}$ were prepared by appropriate dilutions of the concentrated acid.

Ammonium chloride solutions of $0.5,1.0,2.0$ and 3.0 $\mathrm{M}$ were prepared by dissolving appropriate amounts of salt in $500 \mathrm{~mL}$ of water.

The $1000 \mathrm{mg} / \mathrm{L}$ cadmium stock solution was prepared by dissolving $1.3722 \mathrm{~g}$ of cadmium nitrate $\mathrm{Cd}\left(\mathrm{NO}_{3}\right)$ in $2 \mathrm{~mL}$ of concentrated nitric acid, bringing the volume up to $500 \mathrm{~mL}$ with water. Perchloric acid solutions of $0.1,0.2$, 0.3 and $0.4 \mathrm{M}$, containing $500 \mathrm{ng} \mathrm{Cd} / \mathrm{mL}$ were prepared to study the effect of acidity on resin exchange ability. Analytical solutions containing $0.0,2.5,5.0,10.0,15.0,20.0$ and $25.0 \mathrm{ng} \mathrm{Cd} / \mathrm{mL}$ were prepared in $0.25 \mathrm{M}$ perchloric acid by appropriate dilutions of the stock solution.

The certified reference materials used were: NIES 10-b, NIES 10-c (rice) from the National Institute for Environmental Studies, Japan Environmental Agency; TORT-1 (lobster tomalley) from the National Research Council, Canadá (NRCC); and Copepoda (fish) from the International Atomic Energy Agency (IAEA). Acid digests were obtained by digesting $1000 \mathrm{~g}$ of each sample with nitric and perchloric acids according to the procedure described else- 
where ${ }^{15}$, and them bringing the volume up to $100 \mathrm{~mL}$ with water.

\section{Flow diagrams and experimental variables}

The manifold outlined in Fig. 1 was designed to study the main parameters which could affect sensitivity and system performance. The sliding bar of the injector is in the loading position and the sample solution is pumped through both loop L2 and resin column C1 towards waste W. Loop L2 was previously loaded with the Co solution for resin conditioning, which is transported through the column by the sample stream, while loop L1 is loaded with the Es eluant solution. When the sliding bar of the injector is displaced to the other resting position (hatched area), the carrier stream Cs flows through both loop L1 and the resin column. In this position, the aliquot of the eluant solution loaded into $\mathrm{L} 1$ in the previous step is transported through the resin column performing elution. The analyte ions released from the resin are transported by the carrier stream towards the detector through the flow line $\mathrm{L}$. When the elution step is completed, the injector is switched back to start the another analytical cycle. A $2.0 \mathrm{M}$ ammonium chloride solution was used as eluant and as the conditioning reagent in the initial tests.

Unless otherwise mentioned, a $500 \mathrm{ng} / \mathrm{mL}$ cadmium analytical solution was used in the following experiments. The effect of the column loading flow-rate was investigated by settling the following parameters: time intervals for loading and elution of 48 and $16 \mathrm{~s}$, respectively, and an eluant flow-rate of $4 \mathrm{~mL} / \mathrm{min}$. The experiments involved sampling flow-rates of 1.0, 2.0, 4.0, 6.0,8.0 and $10.0 \mathrm{~mL} / \mathrm{min}$. Eluant flow-rates of 2.0, 4.0,6.0, 8.0 and

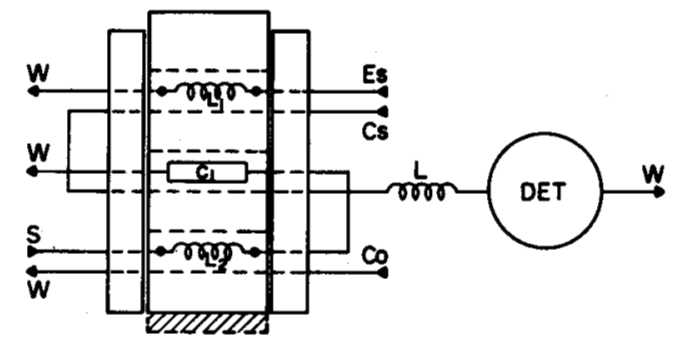

Figure 1. Flow diagram of the set up with a single column. The three rectangular surfaces are an overview of the automatic injector in the loading position. The hatched surface indicates the displacement of the sliding bar to the eluting position; $\mathrm{L} 1$ and $\mathrm{L} 2=20 \mathrm{~cm}$ sampling loops for eluant and resin conditioning solutions; $\mathrm{Cl}=$ resin column; $\mathrm{L}=25 \mathrm{~cm}$ long tubing; DET = atomic absorption spectrometer; $\mathrm{Es}=$ eluant solution at 1.0 $m L / \mathrm{min} ; \mathrm{Cs}=$ water carrier stream (for flow-rate see text); $\mathrm{Co}=$ conditioning solution at $1.0 \mathrm{~mL} / \mathrm{min} ; \mathrm{S}=$ sample (for flow rate see text); and $\mathrm{W}$ $=$ waste. Arrows indicate flow directions.
$10.0 \mathrm{~mL} / \mathrm{min}$ were tested by fixing the column loading time at $48 \mathrm{~s}$, and the sampling flow-rate at $4 \mathrm{~mL} / \mathrm{min}$.

The influence of the column loading time on the magnitude of the analytical signal was investigated, by keeping the injector in the loading position for $32,48,64,80,96$ and $112 \mathrm{~s}$, and then eluting for $16 \mathrm{~s}$. To perform these experiments, flow-rates of $4 \mathrm{~mL} / \mathrm{min}$ were fixed for both sample and eluant solutions.

The effect caused by variations of eluant pre-concentration on the magnitude of the analytical signal, was studied by fixing the sample loading time at $48 \mathrm{~s}$, the elution time at $16 \mathrm{~s}$, and the sample flow-rate and elution flow-rate at $4 \mathrm{~mL} / \mathrm{min}$. As eluants ammonium chloride $(0.5,1.0,2.0$ and $3.0 \mathrm{M})$ or hydrochloric acidic $(1.0,2.0,3.0$ and $4.0 \mathrm{M})$ solutions were used.

To evaluate the resin efficiency for adsorbing ions from the solutions flowing through the column, the effluent waste was collected while the resin column was loaded with a $500 \mathrm{~g} / \mathrm{L}$ cadmium working solution. The column loading time was fixed at $48 \mathrm{~s}$ and the column effluent was collected during the number of analytical cycles necessary for collecting at least $25 \mathrm{~mL}$ of the effluent solution. Cadmium was determined in this effluent solution by employing the same parameters set for the working solutions. Experiments were carried out by employing resins of 50-100 and 200-400 mesh, sampling flow-rates of 2.0, 4.0, 6.0 and 8.0 $\mathrm{mL} / \mathrm{min}$, and a $3.0 \mathrm{M}$ hydrochloric acid solution as the eluant.

The flow network depicted in Fig. 2 was designed to increase the sample throughput. While the sliding bar of the injector rests in the position indicated, the aliquot of eluant solution contained in loop L1 is transported by the carrier stream through the resin columns. The path selecting device (Ps) directs the carrier stream towards the column (C1), where the analyte ions, previously adsorbed by the resin, are released and directed by the carrier stream towards the nebulizer of the atomic absorption instrument. After completing the elution step, the first injector (I) is displaced to the loading position, and while loop L1 is loaded, the analytical path selecting device is rotated to select the analytical path of column (C2). Then, by switching the injector (I) back, the adsorbed analyte ions in the resin column ( $\mathrm{C} 2)$ are released as in (C1). The same operational sequence is employed for columns (C3) and (C4). After the elution steps of all columns have been carried out, the sliding bar of the injector (II) is displaced to the loading position, allowing the resin columns to be loaded again. This set of experiments was repeated for the same column filled with the 200-400 mesh resin.

\section{Results and Discussion}

The flow diagrams (Figs. 1 and 2) were designed to allow the eluant solution to be propelled in a reverse flow mode relative to that employed for loading the resin. This 


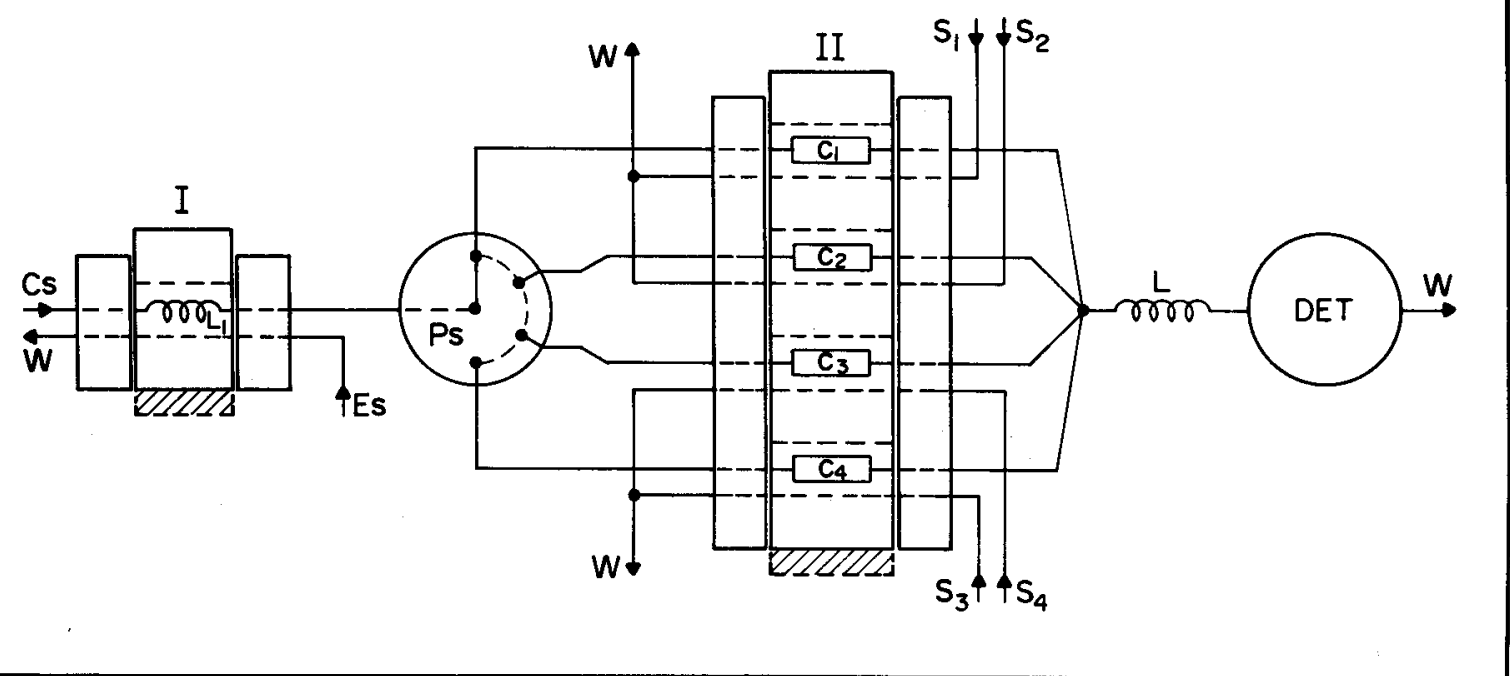

Figure 2. Flow diagram of the set-up with four columns. I and II = automatic injectors with one and four sections. $P_{S}=$ path selector; $S_{1}, S_{2}, S_{3}$ and $S_{4}=$ samples at $4 \mathrm{~mL} / \mathrm{min}$; $\mathrm{Cs}=$ sample carrier solution at $6 \mathrm{~mL} / \mathrm{min} ; \mathrm{C}_{1}, \mathrm{C}_{2} \mathrm{C}_{3}$ and $\mathrm{C}_{4}=11 \mathrm{~mm}$ length and $5 \mathrm{~mm}$ interior diameter resin columns. Other symbols as in Fig. 1.

arrangement avoids excessive compacting of the resin in the column end, minimizing the increase in the internal pressure. This configuration also minimizes the dispersion effect that occurs when the analyte ions are transported through the column during elution.

In the proposed flow networks, the resin column was attached to the sliding bar of the injector. With this configuration, the loading flow-rate and the loading time were the main parameters affecting ion adsorption. Consequently, it could be expected that analytical signal magnitudes were highly dependent on these two parameters. The volume of the analytical solution propelled through the column was calculated as a function of both column loading time and flow-rate. With these data the curves shown in Fig. 3 were plotted.

As can be seen in this Figure, the analytical signals increased in both cases, nevertheless, the proportionality decrease quickly in curve 1 , where the volume of the analytical solution pumped through the column was higher than $4 \mathrm{~mL}$. This volume corresponds to a flow-rate of 5 $\mathrm{mL} / \mathrm{min}$. When the average ion velocity through the resin column increases, the ability of the resin to adsorb ions from the flowing solution may be affected, yielding the asymptotic behavior observed. This assumption can be corroborated by taking into account that for curve 2 , similar behavior was observed only when the pumped volume was higher than $5.3 \mathrm{~mL}$. On the other hand, when the loading flow-rate was lower than $4 \mathrm{~mL} / \mathrm{min}$ (curve 1), the recorded analytical signals were higher than those of curve 2 . This indicates a better ability of the resin to remove ions from the solution when the flow-rate is low. These curves present a point of intersection when the volume pumped through

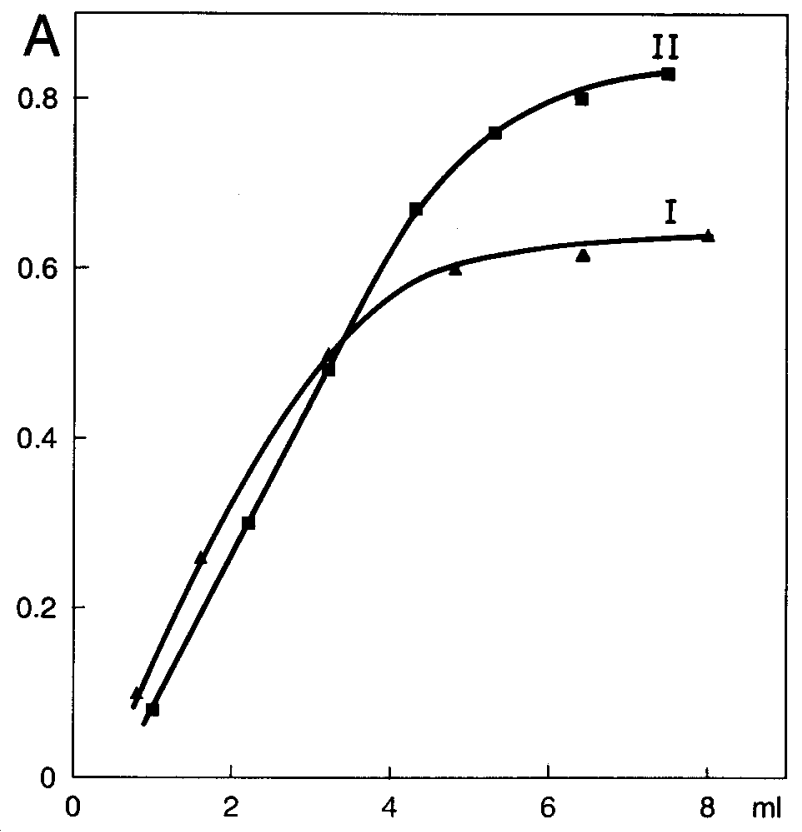

Figure 3. Effect of sampled volume as a function of flow-rate and sampling time. Curve I was obtained with column loading flow-rates of $0.8,1.6,3.2,4.8,6.8$ and $8 \mathrm{~mL} / \mathrm{min}$ and a loading time $=48 \mathrm{~s}$. Curve II was obtained with column loading times of $16,32,48,64,80,96$ and $112 \mathrm{~s}$ and a loading flow-rate $=4 \mathrm{~mL} / \mathrm{min}$. Eluant $=2.0 \mathrm{M}$ ammonium chloride solution. Analytical solution $=500 \mu \mathrm{g} \mathrm{Cd} / \mathrm{L} . \mathrm{A}=$ absorbance and $\mathrm{mL}=$ volume calculated considering loading flow-rates or sampling times. Eluant flow-rate $=4 \mathrm{~mL} / \mathrm{min}$.

the column was $3.4 \mathrm{~mL}$. One can deduce that this volume is associated with a flow rate of $4.3 \mathrm{~mL} / \mathrm{min}$ for curve 1 , and with a loading time of $51 \mathrm{~s}$ for curve 2 . These values present good agreement with those fixed to achieve the data 
used to plot these curves. Curve 2 is practically linear up to a volume of $5 \mathrm{~mL}$, also presenting asymptotic behavior beyond this point, which is less pronounced than that observed in curve 1 . In this instance, it is more profitable to increase the column loading time to improve the limit of detection, instead of increasing the loading flow-rate.

The ability of the resin to exchange ions from a flowing solution can be influenced by the physical structure of the resin, and by the chemical nature of the functional group. In the AG50W-X8 resin, the exchanger is a sulphonic group, also presenting a structure with a high level of cross-linking ${ }^{8}$. This structural characteristic presents as the advantage of a low swelling effect, therefore it can become a hindrance to solution penetration, mainly when the loading flow-rate is increased. This assumption perhaps explains the effect observed in the curves of Fig. 3, when the pumped volume of the analytical solution was higher than $4 \mathrm{~mL}$.

The hydrodynamic impedance of the flow system becomes higher when a resin column is coupled to the flow network. In this instance, granulate resin can exert a remarkable effect, requiring tightened joint points, mainly when a resin with small particle size is used. Resin exchange capacity is not dependent on its granulation ${ }^{8}$. Considering this feature, experiments were carried out to ascertain the ability of the resin to adsorb ions from an analytical solution flowing through the column. The results are shown in Fig. 4, and as can be seen, the resin sieved with a mesh between $200-400$ presented better results. The analyte concentration in the column effluents increased with the loading flow-rate; however, it was higher when the 50-100 mesh resin was used. This result could be associated with the combination of two simultaneous effects. The dead volume of the column increases with the particle size of the resin while the total resin surface diminishes. In this instance, when the loading flow-rate increases, the contact of the analyte ions with the resin exchange sites is impaired, resulting in a decrease in efficiency. Considering these results, the 200-400 mesh resin was selected for the subsequent experiments.

Some tests were also performed to study the effect of eluant concentration. Ammonium chloride and hydrochloric acid solutions were used as eluant solutions. Better results were achieved with a $2.0 \mathrm{M}$ ammonium chloride solution or with a $3.0 \mathrm{M}$ hydrochloric acid solution. Since the analytical signal presented practically the same magnitude, the hydrochloric solution was selected as the eluant. An elution flow-rate of $4 \mathrm{~mL} / \mathrm{min}$ yielded better results and was therefore selected.

Since sample digests presented an acid concentration about $0.25 \mathrm{M}$, some tests were performed to ascertain its effect. No significant difference in the analytical signal was observed for acid concentrations of $0.15,0.30$ and $0.40 \mathrm{M}$. These results could be expected, since this resin presents features similar to a strong $\mathrm{acid}^{8}$, providing facilities for exchanging hydrogen ions with metallic ions from the solution. Based on these results and considering the sample digestion procedure, the working analytical solutions were made of $0.25 \mathrm{M}$ in perchloric acid.

When a resin column is coupled to a flow system to perform on-line pre-concentration, the sample volume pumped through the column is higher than that used in a typical flow system. As a consequence the throughput generally decreases. To overcome this drawback, a flow network with four resin columns was designed. To verify its feasibility a cadmium standard solution was loaded several times, and the results are shown in Fig. 5.

When the resin columns were packed, it was difficult to achieve homogeneity. The difference observed in the recorded peak heights can be ascribed to this fact. Differences between the flow-rate of each pumping channel can also occur. Nevertheless, considering the peak heights of the recorder tracing related to the same column, a good precision was observed, indicating that this approach can be implemented in flow systems. From the same figure a throughput of 80 determinations per hour, can be deduced.

The results obtained with acidic digests of certified reference materials are shown in Table 1. Good agreement was observed between the results obtained with the pro-

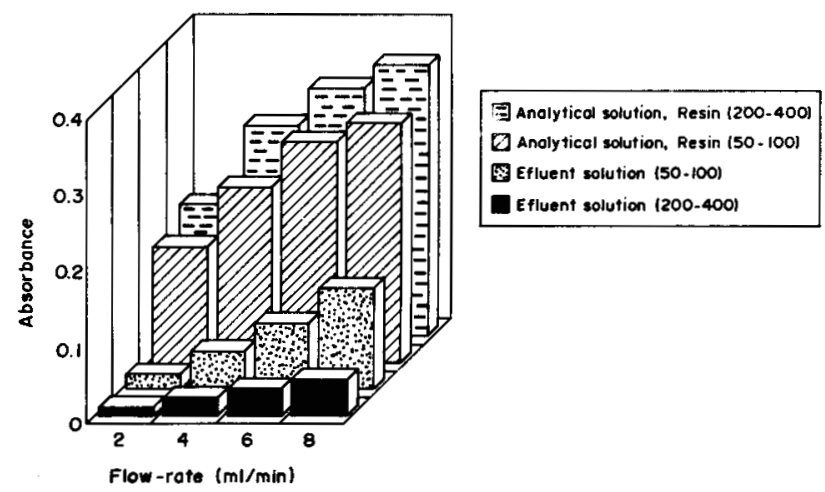

Figure 4. Effect of the resin granulation. Analytical solution $=500 \mu \mathrm{g}$ $\mathrm{Cd} / \mathrm{L}$ and loading time $=48 \mathrm{~s}$. Effluent solutions were collected and further analyzed by employing the same parameters fixed for the analytical solution.

Table 1. Cadmium determinations in certified reference materials.

\begin{tabular}{ccc}
\hline Sample & $\begin{array}{c}\text { Certified value } \\
(\mathrm{ng} / \mathrm{g})\end{array}$ & Found $(\mathrm{ng} / \mathrm{g})$ \\
\hline NIES 10b & $3.2 \pm 0.2$ & $3.6 \pm 0.2$ \\
NIES 10c & $18.2 \pm 0.6$ & $18.1 \pm 0.5$ \\
MA-A-1 & $7.1(6.1-9.0)^{*}$ & $9.4 \pm 0.8$ \\
** TORT-1 & $26.3 \pm 2.1$ & $26.0 \pm 0.5$ \\
\hline
\end{tabular}

* Confidence interval.

** This sample was diluted $1+4$ with $0.25 \mathrm{M}$ before analysis. 


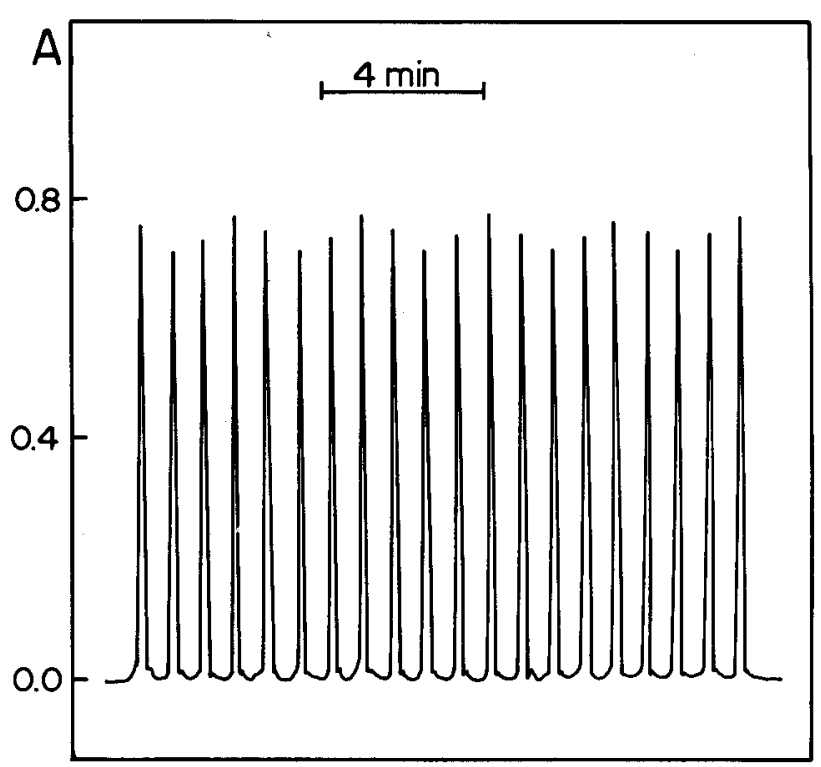

Figure 5. Recorder tracing with the system comprised four columns. From the right, each set of four recorder tracings represents an analytical cycle. A $500 \mu \mathrm{g} \mathrm{Cd} / \mathrm{L}$ standard solution at $4.0 \mathrm{~mL} / \mathrm{min}$ was impelled at the same time through the four columns (Fig. 2) for $48 \mathrm{~s}$; elution was made with a $3.0 \mathrm{M} \mathrm{HCl}$ solution at $4 \mathrm{~mL} / \mathrm{min}$.

posed flow procedure and the certified values. Precision, estimated by the relative standard deviation of the measurements $(n=10)$ was lower than $2 \%$ for a sample containing $20 \mathrm{~g} / \mathrm{L}$ cadmium loaded in the same column. In the proposed flow set-up, the main parameters affecting precision are the rotation speed of the peristaltic pump and the column loading time; therefore overall precision of the results are same as those observed for a single column. The detection limit was $0.7 \mu \mathrm{g} / \mathrm{L}$, calculated as recommended by IUPAC ${ }^{16}$.

\section{Conclusions}

The throughput achieved is considered high for flow analytical procedures involving on-line concentration. The accuracy and the precision of the results were also very good. The results indicate that the AG50W-X8 resin can be used in analytical procedures, beyond presenting profitable features such as tolerance for $\mathrm{pH}$ variations, making simultaneous elution and conditioning possible.

\section{Acknowledgments}

The authors are grateful to FAPESP (Fundação de Amparo à Pesquisa do Estado de São Paulo), CNPq (Conselho Nacional de Desenvolvimento Científico e Tecnológico), CAPES (Coordenadoria de Aperfeiçoamento de Pessoal de Nivel Superior), and FINEP (Financiadora de Estudos e Projetos)

\section{References}

1. J. Ruzicka, Analyst 119, 1925 (1994).

2.B.F. Reis, P.B. Martelli, A.A. Menegário and M.F. Giné, Quím. Nova 16, 109 (1993).

3. M.B. Shabani and A. Masuda, Anal. Chim. Acta 261, 315 (1992).

4. T. Saki and N. Ohno, J. Flow Injection Anal. 10, 2 (1993).

5. Y. Liu and J.D. Ingle Jr., Anal. Chem. 61, 525 (1989).

6. O. Olsen, L.C.R. Pessenda, J. Ruzicka and E.H. Hansen, Analyst 108, 905 (1984).

7. Chelex-100 and Chelex-20 Chelating Resin Instruction Manual (Bio-Rad Laboratories, Richmond, Harbour Way South, Richmond, CA, 94440).

8. AG50W-X8 Resin Instruction Manual (Bio-Rad Laboratories, Richmond, Harbour Way South, Richmond, CA, 94440).

9. M.M. Santos $\mathrm{F}^{\mathrm{a}}$, B.F. Reis, H. Bergamin $\mathrm{F}^{\circ}$ and N. Baccan. Anal. Chim. Acta 261, 339 (1992).

10. D.L. Tsalev and Z.K. Zaprianov, In: Atomic Absorption Spectrometry in Occupational and Environmental Health Practice (CRC Press Inc., Boca Raton, 1983).

11. S. Caroli, A. Alimonti and F. Petruci, Anal. Chim. Acta 248, 241 (1991).

12. M.F. Giné, J.A. Nóbrega, F.J. Krug, V.A. Sass, B.F. Reis and H. Berndt, J. Anal. Atomic Spect. 8 (2):243, 1993.

13. B.F. Reis, M.F. Giné and E.A.M. Kronka, Quím. Nova 15, 231 (1992).

14. B.F. Reis, M.F. Giné, M.M. Santos $\mathrm{F}^{\mathrm{a}}$ and N. Baccans, J. Braz. Chem. Soc. 3, 80 (1992).

15. F.J. Krug, H. Bergamin F, E.A.G. Zagatto and S.S. Jorgensen, Analyst 102, 503 (1977).

16. IUPAC Analytical Methods Committee, Analyst 112, 199 (1987).

FAPESP helped in meeting the publication costs of this article 